\title{
The experiment results of using the competency-based approach in the occupational safety management field to reduce microtraumas in the energy sales company
}

\author{
Elena Bakiko, ${ }^{1,}$, Vitaly Serdyuk ${ }^{1}$, Vladimir Kuleshov ${ }^{1}$, and Ivan Ignatovich ${ }^{1}$ \\ ${ }^{1}$ Omsk State Technical University, Department of Industrial ecology and safety, 644050 Omsk, Russia
}

\begin{abstract}
Reducing injuries problems in the electrical energy industry require the modern tools search and application for managing professional risks. The authors suggest the labor protection services specialists' professional competence improving in organizations as one of these tools. Conducting experiment of the labor protection specialists' professional competence improving impact assessment on the labor protection management effectiveness of was performed on the example of the energy sales company. The experiment purpose was the electrical injuries level decrease. The competency-based approach testing in the labor protection field is based on the researches results of more than 1000 organizations, where the assessment of more than 2000 labor protection specialists' professional competence state was performed. The results obtained showed the occupational safety specialists professional competence improving effectiveness not only in electrical injury reducing by 1.5 times over 2 years, but also in the occupational safety management system effectiveness improving in the company as a whole. The authors forecast the further positive company's competence approach impact in the labor protection field in dynamics. The experiment results are of practical interest to the labor protection services heads, personnel management services, leading top managers, employers.
\end{abstract}

\section{Introduction}

International policy in the occupational safety management field, the occupational safety specialists associations activities are focused on reducing occupational diseases, occupational injuries, stress, as well as managing occupational risks [1-2].

The labor protection management effectiveness improving is one of the most relevant research areas [37]. The necessity to find ways to reduce occupational injuries is noted in the researches of many foreign authors [8-10]. Research results show that a high injuries level leads to large capital losses in the organization [1112]. The fatal injuries consequence in the world was about 2.34 million dead people [13-14].

One of the tools for reducing injuries is the directorate and employees involvement in occupational safety management [15-17]. An effective management tool is the analysis and accounting of the negative production risks impact on employees [18].

International practice and the best practices using in reducing injuries shows the effectiveness of accounting not only for microtraumas, but also for near misses (minor discrepancies). The system organization for microtraumas, incidents recording and their analysis is a task for occupational safety specialists (safety managers). The authors' research shows that the effectiveness of such work depends on their qualifications and professional competence [19-20].

Since 2015, when Vladimir Putin at the G-20 Antalya Summit declared Russia's commitment to the Vision Zero concept, the directorate of the energy sales company under study has set this concept principles implementing task to the labor protection service.

The management's commitment to this concept and the labor protection service work in the energy sales company showed a positive result - a reduction in injuries in the period 2014-2017. However, the electrical microtraumas state remained at an unacceptable level. In 2017 the company used the competency-based approach as a tool for microtraumas reducing at the authors' suggestion. It is aimed at the labor protection service specialists' professional competence level increasing, which contributes to the effective labor protection management in the company.

\section{Methods}

We used empirical research methods (observation, comparison, measurement, experiment), statistical analysis and synthesis.

Experiment results forecasting is based on the author's researches on the occupational safety specialists professional competence level impact on the industrial injuries level, conducted on the basis of more than 1000 
organizations, including energy sales companies, which employed more than 2000 occupational safety specialists from 18 regions of Russia for the period 2014-2019 [19, 21].

\section{Results}

The consistently high energy sales company employees electrical injuries level associated with their work makes the management continuously search for methods and means to effectively prevent these undesirable and adverse events [22].

The initial injuries analysis showed that in the period from 2007 to 2019, 95 accidents of various severity occurred in the company under study (Fig. 1,2).

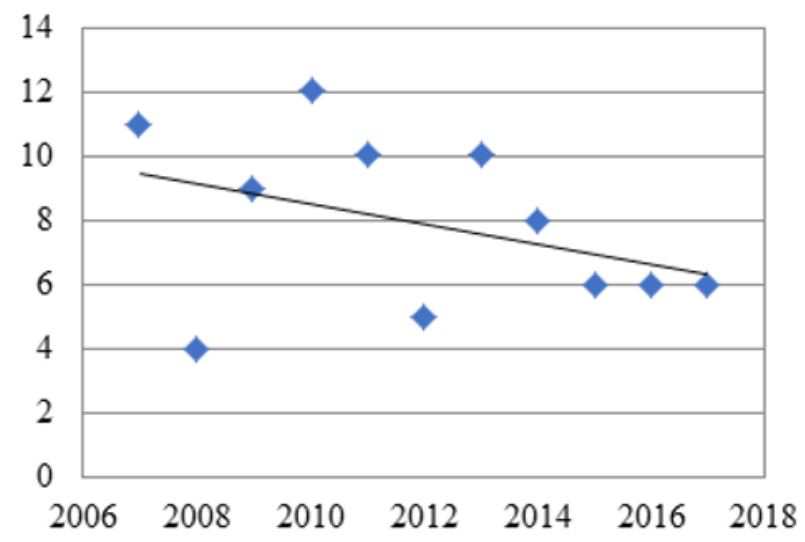

Fig. 1. Accidents number dynamics in an energy sales company.

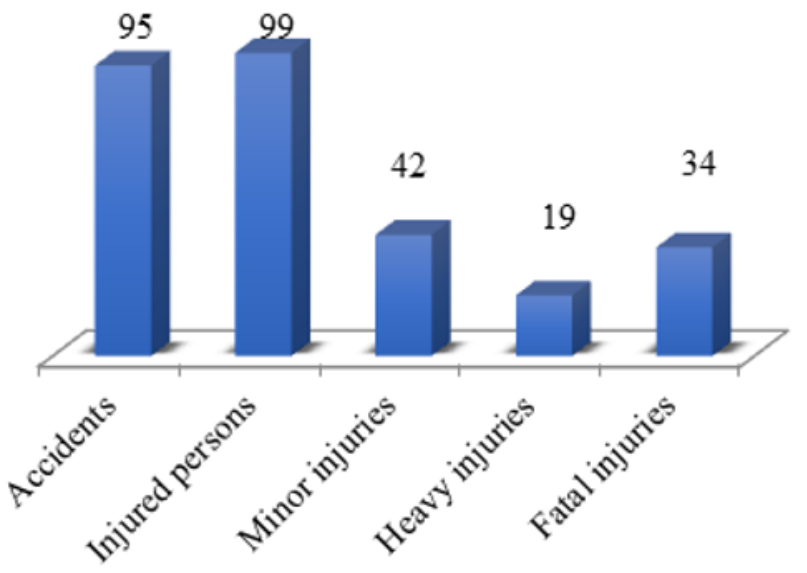

Fig. 2. Injury rate in the energy sales company for the period $2007-2019$.

At the experiment initial stage the labor protection service specialists' professional competence level assessment of studied energy sales company in the Omsk region was performed. By the expert method the authors rated it as an average level. Service specialists had higher education, but not specialized education, professional retraining, periodically passed advanced training courses and had work experience of 3 years or more [19].

The authors suggested the company to use a competency-based approach to improve the labor protection management effectiveness, which is associated with labor protection specialist professional competence level increasing. Therefore, in 2017, the company recruited labor protection specialist with higher level of professional competence- a higher educational institution graduate (Omsk State Technical University) with a master's degree in the field of Technosphere safety with the profile "Labor Safety" without work experience. He was assigned the accounting organizing task of not only accidents and occupational diseases, but also the accounting and analysis of microtraumas, circumstances and causes of their occurrence.

According to the authors' forecast - as a result of the occupational safety specialist professional competence level increasing in the studied company, the procedures implementation for microtraumatism accounting and analysis will be expertly organized, reducing microtraumatism rate by at least $1.5-2$ times in the dynamics over 5 years.

The authors' expert opinion, supported by the experience of testing the proposed approach in other organizations in the region, was convincing for the management. For example, according to the OJSC "Russian Railways" activities report in the sustainable development field for 2017 labor protection measures, including measures for recording and registering microtraumas, allowed for a 3 -fold reduction in injuries over 7 years.

The experiment next stage showed that a specialist of a higher professional competence level, in accordance with the task set by the management, considered the possibility of using the "Accidents pyramid model" for analyzing injuries in the company. It properly illustrates the relationship between accidents, incidents and near misses in the organization [23].

The analysis showed that in the context of the company, the top layer is "accidents, including fatalities". They are subject to investigation and registration. Corrective measures are being developed for prevention and preventing similar cases.

The middle layer is "incidents with less severe consequences", namely cases of disability, which are also recorded. This reduction in injuries is provided by the existing average labor protection service specialists professional competence level (the injuries level in 2015-2017 in Fig 1).

The lower layer is "incidents with minimal consequences (discrepancies)", including electrical microtrauma, which can pass unnoticed, so it is not taken into account.

During the experiment, a specialist with an increased professional competence level ensured the electronic "Incidents and near misses register" introduction in a number of company structural divisions for 3 months. It is important that the recordings were made in a nonpersonalized manner.

Due to active departments' heads involvement to the microtraumas accounting process the following intermediate result was obtained:

1. One-third of top managers considered these labor costs non-production; 
2. One-third of top managers stated obtaining positive results in their units;

3. The company's management positively considered the issue of journal mandatory and regular maintenance in all structural company divisions in the short term. After a month of logging "undervalued" improper operations monitoring increased. It has become obvious that this is an effective way to predict the number and type of microtraumas and accidents; differentiated work state assessment to reduce microtraumas in departments; underestimated detection;

4. Labor protection specialists have noted an increase in the volume of information about the true and reliable improper operations causes. This allowed them to develop effective measures to reduce the number of electrical microtraumas opportunely and in a speedy fashion.

5. The "Accidents pyramid " for 2019 was built in the ratio of 4: 41:1912, from which it follows that for 1 accident in the company there are 10 incidents, and for 1 incident there are 478 near misses.

\section{Discussion}

At the final stage of the experiment, after two years, the following result was obtained:

1. Reducing the number of near misses, microtraumas, accidents (Fig. 3). Reducing the accidents consequences severity;

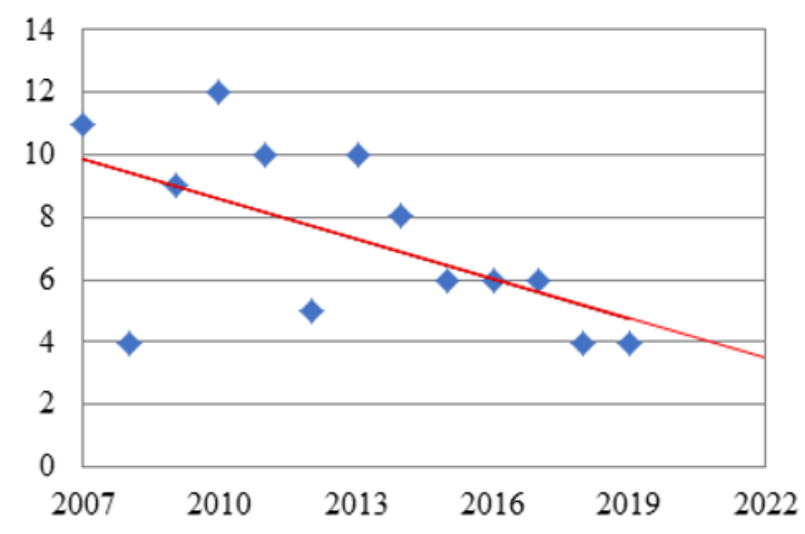

Fig. 3. Reduction of injuries as the occupational safety specialist competence improving result.

2. Company socio-economic losses reduction for reasons related to accidents and microtraumas;

3. Company occupational health and safety management system effectiveness improving;

4. Increasing the motivation of directorate and divisions direct line managers in managing professional risks;

5. Analytical electronic resource emergence for quantitative and qualitative safety improper operations assessment in divisions;

6. Increase in the complexity associated with maintaining the register has led to a decrease in the complexity of preparing weekly (and monthly) job inspections reports. All the necessary information has been pre-processed and structured. In 2020, an automatic service was developed in the company's electronic document flow structure whereby the heads of departments will be able to record all incidents on a daily basis. At the same time, the inspections results reports in divisions are automatically generated;

7. Improving the accuracy of the information provided. The workplaces planned regular inspections results formal filling percentage has decreased;

8. Employee training effectiveness improving on labor protection issues in the company by analyzing the identified reliable improper operations causes;

9. Continuing and improving the working group effectiveness on microtraumas reducing in the company, according to the authors' forecasts, will lead to a continuing injuries reducing trend;

10. Emergence of interest in this solution applying experience from other energy sales companies at the regional level.

Thus, the competency-based approach using by the directorate of the studied energy sales company in the labor protection field to reduce injuries and microtraumas showed a positive result in the period 2017-2019. The labor protection specialists professional competence improving allowed reducing the number and severity of accidents in the company by at least 1.5 times in the first 2 years. The company is expected to continue positive dynamics in the short term.

\section{References}

[1] J. Verbeek, I. Ivanov, Essential occupational safety and health interventions for low-and middleincome countries: an overview of the evidence, Safety and health at work 4, 2, 77-83 (2013).

[2] A.M. Elin, Labor Protection and Economics, Working conditions control as a managerial influence factor 4, 17, 4-8 (2014).

[3] D.C. Darabont, C. Bejinariu, I. Ionita, M.A. Bernevig-Sava, C. Baciu, E.R. Baciu, Considerations on improving occupational health and safety performance in companies using ISO 45001 standard, Environmental Engineering \& Management Journal (EEMJ) 17, 11 (2018).

[4] A. Górny, Assessment and management of risk in improving the OHS management system, System Safety: Human-Technical Facility-Environment 1, 1, 105-111 (2019).

[5] T. Jordan, The ISO 45001: 2018 Implementation Handbook: Guidance on Building an Occupational Health and Safety Management System, Quality Progress 52, 1, 54-54 (2019).

[6] L. Morgado, F.J.G. Silva, L.M. Fonseca, Mapping Occupational Health and Safety Management Systems in Portugal: outlook for ISO 45001: 2018 adoption. Procedia Manufacturing 38, 755-764 (2019).

[7] H. Lingard, Occupational health and safety in the construction industry, Construction management and economics 31, 6, 505-514 (2013).

[8] M.A. Rodrigues, A. Sá, D. Masi, A. Oliveira, G. Boustras, S. Leka, F. Guldenmund, Occupational Health \& Safety (OHS) management practices in micro- 
and small-sized enterprises: The case of the Portuguese waste management sector, Safety Science 129, 104794 (2020).

[9] P. Swuste, C. van Gulijk, J. Groeneweg, F. Guldenmund, W. Zwaard, S. Lemkowitz, Occupational safety and safety management between 1988 and 2010: review of safety literature in English and Dutch language scientific literature. Safety science 121, 303-318 (2020).

[10] R.C. Sinclair, T.R. Cunningham, P.A. Schulte, A model for occupational safety and health intervention diffusion to small businesses, American journal of industrial medicine 56, 12, 1442-1451 (2013).

[11] P. Yakovlev, R.S. Sobel, Occupational safety and profit maximization: Friends or foes?, The Journal of Socio-Economics 39, 3, 429-435 (2010).

[12] E.V. Bakiko, V.S. Serdyuk, E.V. Yakovleva, Omsk Scientific Bulletin. Series Society. History. Modernity, Socio-economic impact of adverse working conditions and their differentiation 4, 4, 149-156 (2019).

[13] X.B. Liu, H.B. Liu, D.D. Han, Current situation and analysis of occupational safety and health in the world, Mod. Occup. Saf. 3, 91-93 (2016).

[14] H. Chen, C. Hou, L. Zhang, S. Li, Comparative study on the strands of research on the governance model of international occupational safety and health issues, Safety science 122, 104513 (2020).

[15] M. Simard, A. Marchand, The behaviour of first-line supervisors in accident prevention and effectiveness in occupational safety, Safety science 17, 3, 169-185 (1994).

[16] B. Fernández-Muñiz, J.M. Montes-Peón, C.J. Vázquez-Ordás, Safety climate in OHSAS 18001certified organisations: Antecedents and consequences of safety behavior, Accident Analysis \& Prevention 45, 745-758 (2012).

[17] A. Skład, Assessing the impact of processes on the Occupational Safety and Health Management System's effectiveness using the fuzzy cognitive maps approach, Safety science 117, 71-80 (2019).

[18] M. Kim, I. Lee, Y. Jung, International project risk management for nuclear power plant (NPP) construction: Featuring comparative analysis with fossil and gas power plants, Sustainability 9, 3, 469 (2017).

[19] E.V. Bakiko, V.S. Serdyuk, V.V. Fadeeva, Omsk Scientific Bulletin, Series Society, History. Modernity, Organizational and economic aspect of labor protection specialist professional competence formation 5, 2, 160-168 (2020).

[20] S.P. Voroshilov, N.N. Novikov, G.Z. Feinburg, Occupational health and safety in construction, Fundamentals of the methodology for assessing the level of professional risk of an employee due to the level of his professional competence 5 (2011).

[21] V.V. Kuleshov, E.V. Bakiko, V.S. Serdyuk, Development of Additional Education to Increase the Level of Competence of Specialists in the Field of Technosphere Safety, International Scientific Conference Far East Con (ISCFEC 2020), 2744-2749 (2020).

[22] A.C. Ahmad, I.N.M. Zin, M.K. Othman, N.H. Muhamad, Hazard Identification, Risk Assessment and Risk Control (HIRARC) Accidents at Power Plant,
EDP Sciences, MATEC Web of Conferences 66, 00105 (2016).

[23] S. Yusupova, Application of international indicators for the analysis of industrial injuries at the Zhezkazgan processing plant, 1, LLP Kazakhmys Corporation, The Works Of The University 1, 78-81 (2016) 